\title{
A CLEMENTINE II MISSION TO THE ASTEROIDS
}

\author{
A. S. HOPE, B. KAUFMAN, R. DASENBROCK
}

Naval Research Laboratory, Washington, D.C., USA

AND

D. BAKERIS

AlliedSignal Technical Services, Greenbelt, Maryland, USA

\begin{abstract}
Clementine II is a Department of Defense (DoD) and industry interplanetary mission designed to flyby several asteroids and release science probes that will impact these asteroids. Candidate asteroids were identified and a nominal and backup mission was chosen from these candidates. The mission design is discussed and the baseline encounters are presented. A backup mission is briefly described. A mass breakdown for the baseline mission is provided as well as the proposed mission sensors. The final encounter approach B-Plane errors are determined and analyzed. A final summary of the Clementine II mission is presented.
\end{abstract}

\section{Introduction}

In January 1994 Clementine I was launched to map the Moon and to perform a close flyby $(100 \mathrm{~km})$ of the near Earth asteroids (NEAs) Geographos and Verenia. Clementine I successfully mapped $100 \%$ of the lunar surface but due to an on-board software bug, the spacecraft lost its attitude control fuel during the transfer phase from the lunar orbit to the Geographos transfer trajectory and thus was unable to carry out the asteroid flybys. A complete description of the Clementine I mission can be found in Middour et al. (1995).

In the summer of 1995, the Clementine program office, now at the USAF/ Phillips Laboratory (USAF/PL) made the decision to study a follow-on Clementine II mission to multiple asteroids to complete the original Clementine I goals and to extend those goals. The primary mission of Clementine II is to perform a close, fast flyby of multiple NEAs, to launch science probes which will impact the asteroids, and to image the actual impact. The objectives of the mission are to perform a cost effective and

\section{M. Wytrzyszczak, J. H. Lieske and R. A. Feldman (eds.),}

Dynamics and Astrometry of Natural and Artificial Celestial Bodies, 183, 1997.

(C) 1997 Kluwer Academic Publishers. Printed in the Netherlands. 
stressing space test demonstration and flight qualification of lightweight spacecraft and sensor technologies; to test autonomous navigation and terminal optical navigation techniques for encounter of cold bodies; and to demonstrate the feasibility for quick-reaction observation of near-Earth objects. The Naval Research Laboratory (NRL) which designed, built and integrated the Clementine I spacecraft will perform the same role for Clementine II. The Lawrence Livermore National Laboratories (LLNL) will design and build the science probes with the help of USAF/PL and will also build the suite of sensor instruments. The spacecraft will be operated from the NRL control center used for Clementine I known as the 'Batcave'. The mission will continue the "faster, better, cheaper" philosophy of the Clementine I mission.

The nominal mission design of Clementine II will involve a transfer from an initial low Earth parking orbit in April of 1998 into phasing loops similar to the profile of Clementine I to gradually increase the energy of the orbit and to increase the launch window for the mission while remaining within the $\Delta V$ constraints of the onboard propulsion system.

The first asteroid encounter of 1987 OA will occur in August of 1998 and the second encounter of 1989 UR will occur just four months later in December of 1998. An Earth gravity assist in early May of 1999 sets up the third encounter with Golevka (6489) at the beginning of June. The flyby distance for the three asteroids is currently designed to be $50 \mathrm{~km}$ and a science probe will be released at each encounter to impact the asteroid seconds before the flyby. The science probes are fully autonomous microspacecraft with an approximate mass of $19.4 \mathrm{~kg}$ with guidance, navigation, and control capabilities. The science probes will have a $\Delta V$ capability and will perform the impact autonomously once released from the mother ship. The accuracy for the asteroid positions with respect to the mothership are discussed. The entire mission duration is approximately 400 days and launch is to occur approximately 26 months from the end of the preliminary study completed in March of 1996.

A science team composed of government, industry, and university members similar to that of Clementine I, will be responsible for the analysis and dissemination of the science data gathered on this mission. The Clementine II mission is an ambitious one from both a space technology and an astrodynamics viewpoint. All measurements are to be taken on-board by the mission sensors, the terminal navigation of the spacecraft is to be performed autonomously to bring the spacecraft within the desired flyby distance, and the impact of the asteroids is to be performed autonomously by the science probes. Various experiments in autonomous navigation are to be performed during the cruise phases. As with Clementine I, perhaps the most difficult task is that launch is to occur just two years from approval. 


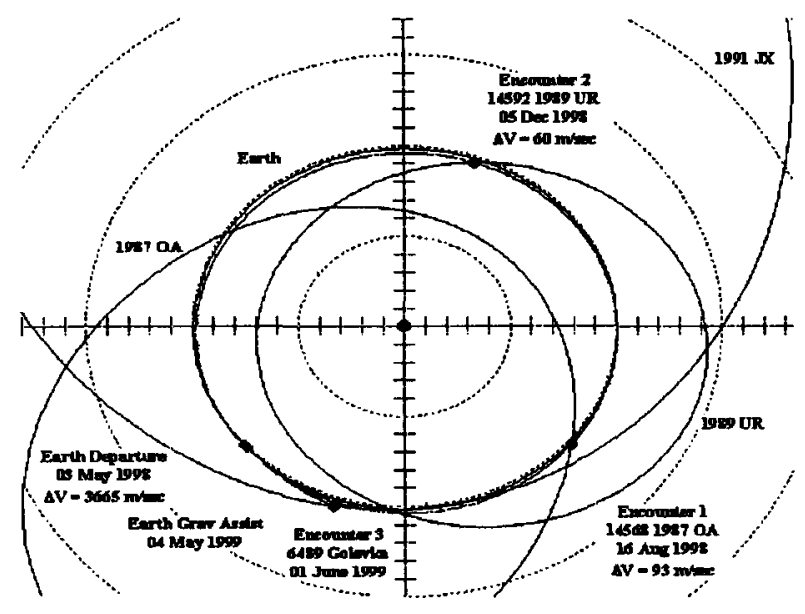

Figure 1. Clementine II baseline trajectory (ecliptic view).

\section{Mission Design}

The primary mission to flyby near Earth Objects (NEO), both asteroids and other objects such as comets, was constrained by a further requirement that the range from the Earth during the encounters would be approximately 0.12 and $0.24 \mathrm{AU}$ for the Deep Space Network (DSN) stations of Goldstone and Arecibo respectively. The launch date of mid-1998 was chosen to allow for a two year development time to launch. The design and launch of the spacecraft was selected to be similar to that of Clementine I. A Titan IIG launched from Vandenberg Air Force Base in California was selected from a trade study of all feasible launch vehicles and launch sites. A STAR 37FMX upperstage solid rocket motor was selected to place Clementine II into its initial phasing loops for Earth departure. The STAR 37FMX is a stretched version of the STAR 37 FM used for Clementine I. It provides more performance for the mission which is required due to a higher launch weight than Clementine I. To decrease flight time and $\Delta V$ requirements, Earth gravity assists (EGA) and deep space maneuvers were allowed in the baseline design.

Under these conditions, a search was performed for NEOs which would make close approaches to the Earth in the 1998 to 2001 time period. Many candidates were found but most were discarded for various reasons such as poor Sun angles or short arc observations of the objects. A total of 13 NEOs remained from which the primary and backup missions were chosen.

The 13 candidates were divided into groups based on Earth closest approach time with a six month granularity allowing for an EGA or a deep space maneuver if necessary, and numerous trajectories were investigated 
TABLE 1. Nominal mission summary.

\begin{tabular}{|c|c|c|c|c|c|c|c|c|}
\hline \multirow{3}{*}{ Depart } & $\begin{array}{c}\text { Depart } \\
\text { Date } \\
{[m / d / y]} \\
\end{array}$ & $\begin{array}{c}\mathrm{C} 3 \\
(\mathrm{LEO}) \\
{\left[\mathrm{km}^{2} / \mathrm{s}^{2}\right]}\end{array}$ & $\begin{array}{l}\text { Dec. Lnch. } \\
\text { Asymptote } \\
\text { [deg] }\end{array}$ & $\begin{array}{c}\text { Dep. } \Delta V \\
(\mathrm{LEO}) \\
{[\mathrm{km} / \mathrm{s}]} \\
\end{array}$ & \multirow{2}{*}{\multicolumn{4}{|c|}{$\begin{array}{c}1987 \text { OA } \\
1989 \text { UR } \\
\text { Golevka }\end{array}$}} \\
\hline & \multirow{2}{*}{\begin{tabular}{|c|}
$05 / 03 / 98$ \\
Event \\
Date \\
{$[\mathrm{m} / \mathrm{d} / \mathrm{y}]$} \\
\end{tabular}} & \multirow{2}{*}{\begin{tabular}{c|}
9.993 \\
Days \\
from \\
Launch
\end{tabular}} & \multirow{2}{*}{\begin{tabular}{|c|}
56.862 \\
$\begin{array}{c}\text { Flyby Body } \\
\text { (number) } \\
\text { (name) }\end{array}$ \\
\end{tabular}} & \multirow{2}{*}{$\begin{array}{c}3.665 \\
\text { Sun } \\
\text { Angle } \\
{[\text { deg }]}\end{array}$} & & & & \\
\hline & & & & & $\begin{array}{l}\text { Flyby } \\
\text { Speed } \\
{[\mathrm{km} / \mathrm{s}]}\end{array}$ & $\begin{array}{c}\text { Earth } \\
\text { Distance } \\
{[A U / k m]} \\
\end{array}$ & $\begin{array}{c}\text { Sun } \\
\text { Distance } \\
{[A U]}\end{array}$ & $\begin{array}{l}\text { Flyby } \\
\text { Mnvr } \\
{[\mathrm{km} / \mathrm{s}]}\end{array}$ \\
\hline ENC 1 & $08 / 16 / 98$ & 104.5 & $\begin{array}{c}14568 \\
1987 \text { OA }\end{array}$ & 10.062 & 17.626 & $\begin{array}{c}0.1236 \\
18490297\end{array}$ & 1.0343 & 0.093 \\
\hline ENC 2 & $12 / 05 / 98$ & 216.3 & $\begin{array}{c}14592 \\
1989 \text { UR }\end{array}$ & 14.455 & 10.481 & $\begin{array}{c}0.0925 \\
13837803\end{array}$ & 0.9715 & 0.060 \\
\hline $\begin{array}{c}\text { Earth } \\
\text { GA }\end{array}$ & $05 / 04 / 99$ & 365.4 & Earth & 79.699 & 3.105 & $\begin{array}{c}39474.3 \mathrm{~km} \\
\mathrm{ALT}\end{array}$ & 1.0082 & 0.000 \\
\hline \multirow[t]{3}{*}{ ENC 3} & $06 / 01 / 99$ & 393.7 & $\begin{array}{c}6489 \\
\text { Golevka }\end{array}$ & 29.709 & 11.001 & $\begin{array}{c}0.0507 \\
7584612\end{array}$ & 1.0508 & \\
\hline & $\begin{array}{c}\text { Post } \\
\text { Departure } \\
\Delta V \\
{[\mathrm{~km} / \mathrm{s}]} \\
\end{array}$ & $\begin{array}{c}\text { Total } \\
\text { Mission } \\
\Delta V \\
{[\mathrm{~km} / \mathrm{s}]}\end{array}$ & $\begin{array}{c}\text { Mission } \\
\text { Duration } \\
\text { [days] } \\
\text { [years] }\end{array}$ & \multirow{2}{*}{\multicolumn{5}{|c|}{$\begin{array}{l}\text { NOTES: } \\
\text { Departure is from Earth-Moon system } \\
\text { Launch date may vary } \\
\text { LEO inclination must be greater than DLA } \\
\text { Depart. velocity is from } 120 \text { nmi. circular LEO } \\
\text { Sun angle of } 180^{\circ} \text { means vel. vector into Sun }\end{array}$}} \\
\hline & 0.153 & 3.818 & $\begin{array}{c}394 \\
1.08\end{array}$ & & & & & \\
\hline
\end{tabular}

which allowed for three flybys. Six candidate trajectories were determined that fulfilled most if not all of the requirements.

\section{Baseline Mission}

The nominal mission sequence of 1987 OA, 1989 UR, and Golevka with an EGA after the second flyby was selected and meets all of the mission requirements. With the launch taking place in late April of 1998, the encounters will take place within 400 days with a total $\Delta V$ requirement of $3818.0 \mathrm{~m} / \mathrm{s}$. An Earth gravity assist (unpowered) will take place after the flyby of 1989 UR. The nominal mission summary is shown in Table 1. A picture of the encounter sequence from an ecliptic perspective is shown in Figure 1. The predicted errors for the asteroid positions (Table 2) were determined by Don Yeomans of JPL and Ted Bowell of Lowell Observatory. They incorporate Earth based optical measurements and radar measurements up until the time of encounter. 
TABLE 2. Predicted asteroid error at time of encounter.

\begin{tabular}{cccc}
\hline Asteroid & $\begin{array}{c}\text { RA Error } \\
{[\mathrm{km}]}\end{array}$ & $\begin{array}{c}\text { DEC Error } \\
{[\mathrm{km}]}\end{array}$ & $\begin{array}{c}\text { Range Error } \\
{[\mathrm{km}]}\end{array}$ \\
\hline 1987 OA & 26 & 30 & 1 \\
1989 UR & 29 & 15 & 1 \\
Golevka & 1 & 1 & 1 \\
\hline
\end{tabular}

\section{Earth Launch and Departure}

The Earth launch and departure scenario was selected to allow freedom in launch date and assure departure of the Earth-Moon system to complete the entire mission within the constraints of the spacecraft capabilities. The scenario includes a launch stack weight of $4300 \mathrm{lbs}$., including a scaled back STAR 37FMX solid rocket motor (SRM). The stack will be launched into a $120 \times 120 \mathrm{nmi}$., 67 degree inclination Earth orbit by a Titan IIG launch vehicle. The lifetime of this initial orbit was determined to be approximately 8 days for the predicted solar cycle values. The launch date was selected to be approximately 18 days before the required Earth departure date. This allows for a launch window of approximately two weeks, a one day stay in LEO for system checkout and one approximately three day phasing loop after the SRM firing. If launched at the beginning of the launch window, the remaining time would be spent in several three day phasing loops with trim maneuvers to assure proper timing for Earth departure. A similar strategy was used for Clementine I (Soyka, 1995).

Analysis of the sensitivity of required mission $\Delta V$ on Earth departure date was conducted. The change in mission $\Delta V$ for a three day advance or slip in Earth departure date was calculated to be nearly $+30 \mathrm{~m} / \mathrm{s}$ per day. This $\Delta V$ increase was found to occur after the first encounter with 1987 OA to set up the second encounter with 1989 UR.

\section{Backup Mission}

The backup mission of 1989 UR, 1992 SK, and Golevka (6489) has a launch date of August 1998 and a slightly higher total mission $\Delta V$ which makes this an excellent candidate for a backup mission. An EGA is also not required which simplifies mission operations. The mission duration for the backup mission is less than 300 days which is also very desirable. The Sun angles are not as desirable for this backup mission as for the nominal mission and additionally there is no possibility for a launch slip for this backup mission. More detailed information on this backup mission can be found in (Bakeris et al., 1996). 


\section{Spacecraft Top-Down Mass Analysis}

A top-down mass analysis was performed to determine a nominal dry spacecraft weight based on known quantities of fuel and launch vehicle capabilities. It was assumed that a bi-propellant motor identical to Clementine I would be used for the mission. The initial orbit was assumed to be a $120 \times 120 \mathrm{nmi}$ orbit with a $4300 \mathrm{lb}$. payload, which is within the performance capabilities of the Titan IIG. To perform this analysis, correction maneuver and final guidance fuel were budgeted. Table 3 shows the breakdown of weight for the initial spacecraft at the time of launch. This paper presents only a top down analysis. Extensive bottom up analyses have been performed, but are not included in this paper.

TABLE 3. Spacecraft weight breakdown from top down analysis.

\begin{tabular}{lc}
\hline Spacecraft Item & Weight [lb.] \\
\hline Dry Spacecraft & 628.04 \\
Interstage Weight & 68.3 \\
SRM Burnout Weight & 194.0 \\
Payload Adapter Faring & 61.3 \\
Microsatellites (3) & 128.31 \\
SRM Extras (ablatives) & 26.0 \\
Bi-propellant Fuel & 432.05 \\
SRM Fuel & 2730 \\
Monopropellant Fuel & 32.0 \\
\hline
\end{tabular}

The amount of SRM fuel was adjusted to provide nearly $3000 \mathrm{~m} / \mathrm{s} \Delta V$ for the full stack after separation from the launch vehicle. Interstage and payload adapter faring weight are derived from Clementine I experience. The SRM casing and ablative weights are from the SRM manufacturer. ACS fuel is based on Clementine I and the magnitude of maneuver $\Delta V s$ required for the mission. The microsatellite weight is derived from estimates of the total subsystem weights and support and thermal structure. The bi-propellant fuel load includes unusable fuel as well as correction and contingency fuel.

\section{Spacecraft and Probe Sensors}

The Clementine II spacecraft will contain several sensors integrated on a common optical bench and will utilize a tunable filter system. The imagers, similar to the Clementine I suite, include Ultraviolet/Visible (UV/Vis), Near Infrared (NIR), Medium Wave Infrared (MWIR), and High Resolution (HiRes) sensors, LASER Image Detection and Ranging (LIDAR), and star 
TABLE 4. Results of estimation analysis for B-Plane error.

\begin{tabular}{ccccc}
\hline $\begin{array}{c}\text { Number of } \\
\text { Stars }\end{array}$ & $\begin{array}{c}\text { Meas. } \\
\text { Accuracy } \\
{[\mu \mathrm{rad}]}\end{array}$ & $\begin{array}{c}\text { Meas. } \\
\text { Freq. } \\
{[\mathrm{min}]}\end{array}$ & $\begin{array}{c}\text { Half-Dia Error }[\mathrm{km}] \\
\text { (48 hrs Time to go) }\end{array}$ & $\begin{array}{c}\text { Half-Dia Error }[\mathrm{km}] \\
\text { (6hrs Time to go) }\end{array}$ \\
\hline 3 & 5 & 30 & 12.05 & 1.79 \\
3 & 5 & 60 & 12.76 & 2.32 \\
4 & 5 & 30 & 11.9 & 1.76 \\
4 & 5 & 60 & 12.61 & 2.22 \\
4 & 5 & 120 & 13.68 & 2.99 \\
4 & 5 & 240 & 15.56 & 3.46 \\
4 & 25 & 60 & 26.32 & 5.27 \\
\hline
\end{tabular}

trackers (Nozette, 1995; Regeon et al., 1995), but are evolutionary designs incorporating changes since the original 1993 models. The total mass of the sensor payload is expected to be $25 \mathrm{~kg}$.

Each of the three science probes is a fully autonomous microspacecraft with guidance, navigation, and control capabilities provided by a star tracker, IMU sensors, and an ACS/RCS system. The front of the probe will contain a visible channel CCD imager. The probe will have a propulsion system for axial and longitudinal firings with enough $\Delta V$ for release, in-flight maneuvering, and margin for end-game course corrections. A telemetry link between the mothership and the probe is enabled through a UHF link. The final probe mass will be approximately $19.4 \mathrm{~kg}$ for a maximum operational lifetime of about 3 hours.

\section{B-Plane Error Prediction}

Analysis was performed to determine the precision with which the BPlane penetration point for the Clementine II spacecraft could be determined. The simulation used to generate the performance used the characteristics of the onboard High Resolution (HiRes) camera and initial errors based on estimated position knowledge of the spacecraft and the asteroids. The simulation assumed a miss distance of $70 \mathrm{~km}$ with initial errors of $100 \mathrm{~km}$. Based on the current estimate of the asteroid and spacecraft ephemeris errors near the time of encounter, this is a reasonable assumption. Measurements began 72 hours before the encounter and were taken until 6 hours before the encounter. The camera resolution was assumed to be $5 \mu \mathrm{rad}$ and measurements were taken at intervals varying from 30 to 240 minutes. Each measurement used to determine the B-Plane penetration point was generated assuming that 3 or 4 known stars were visible, along with the asteroid, in the HiRes camera. Table 4 shows the $1 \sigma$ error results 


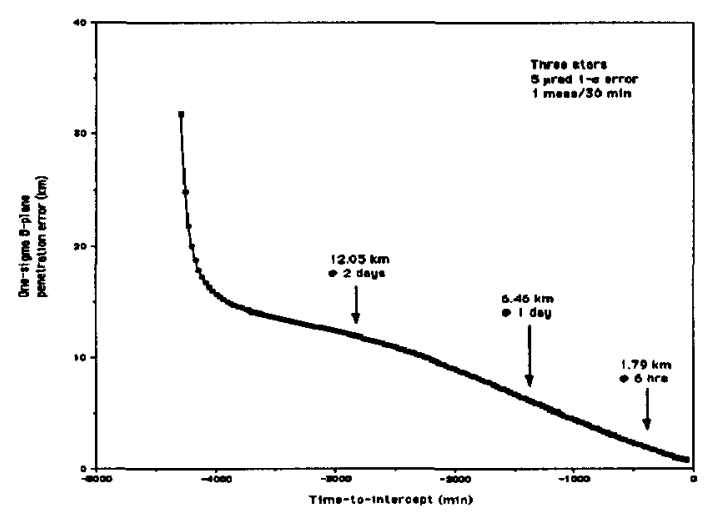

Figure 2. Estimated B-Plane error vs. time to intercept.

for several possible scenarios. The estimated errors were generated by propagating the current covariance to the time of encounter. As can be seen in Table 4, the estimated error for the knowledge of B-Plane penetration point is approximately $2 \mathrm{~km}$ for measurements up until 6 hours prior to encounter. This analysis also showed that no along track information for the encounter can be determined until minutes before the encounter.

Figure 2 shows an error plot for the scenario where measurements were taken every 30 minutes, with $5 \mu \mathrm{rad}$ accuracy and three stars in the background for measurements.

\section{Summary}

Based on the current knowledge of the asteroid ephemerides and the design of the science probes, Clementine II has been baselined as a follow-on to the Clementine I mission objectives and is a viable and exciting sequel to that highly successful mission. A realistic mass, ephemeris, and encounter profile has been designed to fulfill the goals of the Clementine II mission.

\section{References}

Bakeris, D., Hope, A., and Kaufman, B.: 1996, "Clementine II preliminary mission trajectory design", Second IA A International Conference on Low-Cost Planetary Missions, IAA-L-0205.

Middour, J.W.,Dasenbrock, R.R., Kaufman, B., Hope, A.S., and Soyka, M.T.: 1995, "Clementine trajectory analysis", CNES Spacefight Dynamics Conference, Toulouse, France, CNES MS95/038

Nozette, S.:1995, "The Clementine mission", Acta Astronautica, Suppl., 3, 161-169.

Regeon, P.A., Chapman, R.J., and Baugh, R.: 1995, "Clementine - the Deep Space Program Science Experiment (DSPSE)", Acta Astronautica, Suppl., 3, 307-321.

Soyka, M.T.: 1995, "Clementine: contingency options for the phasing loops used in the Lunar transfer”, AAS/AIAA Spacefight Mechanics Meeting, AAS 95-126. 